\title{
Nexus between Work Life Conflict and Work Life Balance
}

\author{
Dr. A.Thilaha Dharmarajan ${ }^{* 1}$, U.Ezhilarasi ${ }^{2}$ \\ Associate Professor ${ }^{1}$, Research Scholar ${ }^{2}$ \\ ${ }^{1,2} P G$ \& Research Dept. of Corporate Secretaryship, Bharathidasan Govt. College for Women (A), Puducherry \\ E mail: dratm71@ rediffmail.com
}

\begin{abstract}
Work-life balance includes a balance between work and personal life that both bring satisfaction to the individual. The quandary for employees that happens today is that when they seek work requests, there is a bounty of adverse consequences on the balance of employees from increased stress, work fatigue, disruption of family and work relationship. In today's scenario, work life balance is an important challenge. This may trigger stress or decrease employee productivity. It is vital to learn more in particular about the consequences of imbalance on family and community and on changing values among younger workers. This paper is an attempt to identify the correlation between both the Work-Life Conflict and Work-Life Balance. Women employees working in two private organizations at Puducherry were the target respondents. Survey is conducted to assess their level of work life balance. This study attempts to identify the difference in the level of Work-Life Balance of the respondents based on their Parental status.
\end{abstract}

Keywords - Work Life Conflict; Work Life Balance; Parental Status.

\section{Introduction}

Balance of work-life is a vital issue for each worker both in government and private sector today. This is on the grounds that there will be a reduction in worker usefulness and execution if an association doesn't contemplate the work equilibrium of employee appropriately and isn't overseen appropriately. In the recent years, emergence of socio-economic trends like mounting number of dual income families and nuclear families, increase in the number of working women, need for constant technological connectivity to work, extended working hours etc. have become part of work life. These changes have brought about a substantial strain on men and women in balancing their work life and family life in this modern period. An imbalance between work and family lives when arises, may result in family conflict, violence, divorce, parenting troubles in the family life; while in work it may result in under performance in all spheres which includes spurt in change of body metabolism. Hence, work- life balance is an emerging priority for the health and wellbeing of employed women, their families, and for overall economic competitiveness.

\subsection{Work life Balance}

Work life Balance is an idea that upholds the endeavors of employees to part their time and energy among work and other significant parts of their lives. Work-Life Balance (WLB) is an everyday work to set aside a few minutes for family, companions, spirituality, selfimprovement, self-care and other individual exercises notwithstanding the requests of the work place. The term work life balance can mean various things to various people and distinctive to similar individual at different focuses in their career. It is a highly individualized and reflexive idea of having the option to deal with one's work, family and relaxation of life in a judicial way.

\subsection{The Imbalance}

The challenge of balancing work and family (nonwork) demands is one of today's main concerns for both individuals and organizations. Individuals who have better equilibrium have a more noteworthy occupation fulfillment and perform better in their position. As the demands of workplace have increased invariably for all ranks of employees, family increasingly bears the burden of balancing work and family. This can result in increased stress and role conflict for workers within the family. Imbalance, especially among work and family, fundamentally influence the nature of everyday life and career achievement.

\subsection{Work- Life Conflict}

Work and family have equally greedy of energy and time and liable for work-family Conflict (WFC) As women are increasingly encouraged to seek self-fulfillment in demanding professions, these struggles are increased by the "social inconsistencies of parenthood", and furthermore face escalated tensions to forfeit themselves for their children by giving "serious nurturing", profoundly involved childrearing and advancement. Employed women have additional problems like finding adequate, affordable access to child and elderly care.

\section{Review of Literature}

Y Adel Ismail Al-Alawi and Eman Al-Saffar,(2021) attempted a study on the effects of work-family conflict

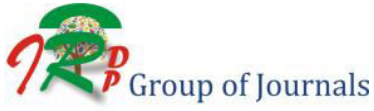


and work-life balance on Saudi female teachers' performance in the public education sector with job satisfaction as a moderator.

Andrea Gragnano, Silvia Simbula and Massimo Miglioretti, (2020) explored the effects of job satisfaction change based on worker characteristics. This study discussed the importance of the health related domain in the work-life balance and stresses that it is crucial to consider the specificity of different groups of workers when considering the WLB.

Christian Wiradendi Wolor at. el., (2020) made a study on the importance of work-life balance on employee performance in Indonesia. This study aims at various theories regarding the effect of the influence of work-life balance on employee performance. Tahani $\mathrm{H}$. Alqahtani(2020) attempted a study on Work Life Balance of Women Employees. This paper explores various literatures related to women employees' work-life balance and confirms that WLB is mandatory for personal satisfaction. Aqeel Ahmed Soomro, Robert J. Breitenecker and Syed Afzal Moshadi Shah (2018) in their study focused on the relationships between work-life balance, work-family conflict, and family-work conflict and perceived employee performance with job satisfaction serving as a moderating variable.

Indu Gautam, Sameeksha Jain (2018) the study identified the existence of negative effects of poor WLB determined by high levels of work-family conflict and family-work conflict on family satisfaction. Also, this study confirmed negative effects of poor WLB due to high levels of work-family conflict on work satisfaction and psychological health. This study also proved that the main causes of work family conflicts were excessive working hours and inflexibility of work schedule. The employers can improve WLB by applying family friendly initiatives such as flexi-time, compressed working week, childcare support and elder care support.

Thriveni Kumari and Dr.Rama Devi (2015) conducted a study on work life balance of women employees in selected service sectors. The study analyse various factors affecting work-life balance and work-life balance of women employees. The researcher has identified 360 women employees working in various sectors in Bangalore like banking, insurance, IT, ITES, health care and education. This research considered 60 employees from each sector. The study revealed that the levels of work-life balance of women employees in service sectors are significantly different.

Yadav at.el. (2013) explored that the respondents have average level of work life balance and they are personally happy with their working arrangements. The findings of the study reveals that balancing care and work affects are needed for career progression. Manager's act as barriers to members achieving appropriate work-life balance and considered it is an important determinant of intrinsic aspects of job satisfaction. Most of the employees enjoy the job and feel comfortable at their work place.

Madipalli S. Sarma \& Chinnappaiah (2013) studied some factors of work life imbalance of female teachers at home and at work place. They observed that ineffective work arrangements, poor working conditions, lower income, long working hours and pressurized working environment may be responsible for monotony, frustration and stress towards work and home, are finally leads to work life imbalance. Marital relationship, attitude and cooperation of husband and family members are the other factors that also relate to WLB amidst working women.

S. Padma (2013) have highlighted the role of family support in balancing personal and work life and found that the present study show that the support from family members will play a major role in balancing both Personal and Professional lives. Especially, employees who have adult children can easily balance than those with young kids. Similarly employees who need to take care of elder parents/in-laws health responsibility have lesser work life balance than their counterparts. The study identified that lower balance may lead to higher absenteeism, lower job satisfaction and sometimes it might turn to higher employee attrition. Organizations with co-operative work culture may help them to bring a suitable balance in their professional and personal life.

In 2013, Hindustan Times made a global survey on working women across 33 countries and they revealed the findings that $72 \%$ of Indian women had turned down their job or did not pursue as they were concerned about its impact on work life balance. Some of the reasons for women quitting jobs included very poor work culture, gossiping and the feeling that their work goes unnoticed.

S. Lakshmi Narayanan et.al (2013) explored the impact of the dependent child's age on the work-family conflict experienced by the working mothers in the IT industries at Bengaluru. In the research paper they tried to determine the impact of the various factors on the workfamily conflict experienced by the working mothers. They concluded that the factors influencing the work-family conflict of the working mothers differs upon the age of their children.

V. Madhusudhan et.al (2013) have identified the factors responsible for work life balance and extracted that dependents, time flexibility, role clarity, co-worker support, family culture, working hours and head support are responsible for work life balance. Management has

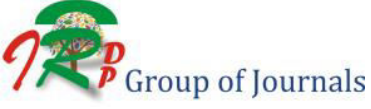


to focus on time flexibility, co-worker support, role clarity, daily working hours and head support for managing work life balance.

K. Santhana et.al (2013) underlined four factors in her study which are, marital status, requirement of flexibility, working hours, additional working hours and over time distort the work life balance. This is more unique in married women, as any additional or extended working hours at the organization deny them the time required to attend to the children and the other dependents. Among the factors classified in to components, the above factors alone influence more than $38 \%$ of work life balance. The study further discloses three factors which are, number of dependents, childcare reasons for overtime i.e. work life balance of married women is affected the basis of the number of dependents at home. This is worsened by the number of small children who need to be cared for and tended [i.e., larger the dependents lesser is the balance and vice versa, the supportive functional head can always help to reduce the consequences of work life balance related.

Ramanithilagam V at. al. (2012) made a study on the work life balance of Indian women employees where, their lives is with multiple roles and daily routine responsibilities at work home. It explores how female workers utilize emotional intelligence competencies in their leadership styles. Careful planning and personal effort were the means to maintain work life balance.

\section{Methodology}

This study aims to bring out the relationship between work-life conflict and work-life balance. The influence of parental status on the work-life balance of women is emphasised. The respondents are women employed in two private organizations at Puducherry.

\section{Objectives of the Study}

The objectives of this study are:

- To study the level of work-life balance of women employed in private organizations at Puducherry.

- To find out the differences in the level of work-life balance caused by parental status.

\subsection{Hypotheses of the Study}

- There is no significant relationship between worklife conflict and work-life balance.

- There is no significant difference in the level of work-life balance caused by parental status.

\subsection{Sample Size}

Data was collected from 311 working in two private organizations located in Puducherry.

\subsection{Respondents Profile}

$32.5 \%$ of the respondents are below 25 years of age. $38.1 \%$ of the respondents are between the age group of 26 and $30.18 .4 \%$ of the respondents are between 31 and 35 years of age and $11 \%$ are above 35 years of age. With respect to designation $41.4 \%$ of the respondents belong to junior level. $34 \%$ belong to middle level and $24.6 \%$ belong to senior leve1. Out of married respondents $19.1 \%$ do not have children, $65.2 \%$ have one child and only $15.7 \%$ of the respondents have two children. $14.9 \%$ of the respondents work in general shift, $2.5 \%$ work in second shift. $24.6 \%$ work in night shift. $57.9 \%$ work in alternative shifts.

\subsection{Results of the Study}

The relationship between work-life conflict, and work life balance was tested through Pearson's correlation test. The results shown in the following Table no. 1 exposes that there is a negative relationship between work life conflict and work life balance.

Table: 1 Mean, Standard Deviation and Correlation

\begin{tabular}{|l|l|l|l|l|}
\hline & Mean & SD & WLC & WLB \\
\hline WLC & 2.44 & 0.91 & 1 & $-0.350^{* *}$ \\
\hline WLB & 2.58 & 0.77 & $-0.350^{* *}$ & 1 \\
& & & 0.000 & \\
\hline
\end{tabular}

$* *$ Correlation significant at 0.01 level (2-tailed)

Table 2: Influence of Parental status

\begin{tabular}{|l|l|l|l|l|l|}
\hline Variable & $\begin{array}{l}\text { No } \\
\text { child }\end{array}$ & $\begin{array}{l}\text { One } \\
\text { child }\end{array}$ & $\begin{array}{l}\text { Two } \\
\text { children }\end{array}$ & $\begin{array}{l}\text { F- } \\
\text { value }\end{array}$ & p-value \\
\hline WLB & $11.46^{2}$ & $11.11^{2}$ & $7.69^{\prime}$ & 34.605 & $0.000^{* *}$ \\
\hline WLC & $15.55^{1}$ & $18.14^{2}$ & 11.583 & 21.031 & $0.000^{* *}$ \\
\hline
\end{tabular}

Note: ** denotes significance at $1 \%$ level, * denotes $5 \%$ level of significance, 1,2 denotes the subgroups as generated by Duncan Multiple Range test

From Table 2, it is evident that there is significant difference between the respondents having no child, having one child and having two children with respect to work-life balance, and work-life conflict. Level of work-life balance is lower (7.69) for respondents who have two children when compared to those who have one child (11.11) or do not have a child (11.46). Work-life balance and work-life conflict differs significantly between respondents having one child, two children and no child. 


\subsection{Findings}

The correlation analysis reveals that there is a negative relationship between the direction of work-life conflict and work-life balance.

The ANOVA reveals that there is significant difference between the respondents having no child, having one child and having two children with respect to work-life balance and work-life conflict.

\section{Conclusion}

The work life imbalance is not a problem of the individual or employer but of the society. The organizations have to create family-friendly organizational culture that facilitates creative solutions to work-life issues. This study highlights some of major factors affecting work-life balance like, one's parental status which includes presence of children or elderly who need constant assistance. To remain competitive and to boost their image as the best employers, companies must address the work-life balance issues using various employee friendly HR measures.

\section{References}

[1] Adel Ismail Al-Alawi*, Eman Al-Saffar, Zahraa Alomohammedsaleh, Hessa Alotaibi, Ebtesam I. Al-Alawi (2021): A study of the effects of work-family conflict, family-work conflict, and work-life balance on Saudi female teachers' performance in the public education sector with job satisfaction as a moderator.vol 22,Journal of International Women's Studies, Issue 1,pp.486-503.

[2] Andrea Gragnano, Silvia Simbula and Massimo Miglioretti, (2020) Work-Life Balance: Weighing the Importance of Work-Family and Work-Health Balance,Int. J. Environ. Res. Public Health, pp.1-20.

[3] Christian Wiradendi Wolor, Destria Kurnianti, Siti Fatimah Zahra, S. Martono, (2020) The importance of work-life balance on employee performance millennial generation in Indonesia, Vol 7 , Journal of Critical Reviews, Issue 9,p-2.
[4] Tahani H. Alqahtani (2020): Work Life Balance of Women Employee, Granite Journal Vol. 4, Iss. no 1,pp.37-42.

[5] Aqeel Ahmed Soomro, Robert J. Breitenecker and Syed Afzal Moshadi Shah (2018) Relation of work-life balance, work-family conflict, and family-work conflict with the employee performancemoderating role of job satisfaction,South Asian Journal of Business Studies, Vol. 7 No.1,p.10.

[6] Indu Gautam, Sameeksha Jain (2018): A Study of Work Life Balance: Challenges and Solutions, International Journal of Research in Engineering, IT and Social Science, pp.198-217.

[7] Thriveni Kumari and Dr.Rama Devi (2015): A Study on Work Life Balance of Women Employees in Selected Service Sector, Pacific Business Review International, Vol.7, Iss.10, pp.17-23.

[8] Yadav, R. K., \& Dabhade, N. (2013). Work Life Balance And Job Satisfaction Among The Working Women Of Banking And Education Sector - A Comparative Study. International Journal of Advancement in Education and Social Sciences, 1(2), pp. 17-30.

[9] Madipelli. S, Sarma.VS V, Chinnappaiah Y (2013): Factors causing work life imbalance among working women-a study on school teachers. The Indian Journal of Industrial Relations. Vol.48 (4), pp. 621-633.

[10] S. Padma, M. S. (2013): Role of Family Support in Balancing Personal and Work-Life of Women Employees, IJCEM International Journal of Computational Engineering \& Management, Vol. 16 Issue 3, May 2013, pp 93-97.

[11] Lakshmi Narayanan et.al (2013) Lakshmi Narayanan. S and Dr.A.Savarimuthu (2013): Work-Family Conflict-An Exploratory Study of the Dependents Child's Age On Working Mothers Rev. Integr. Bus. Econ. Res. Vol.2 (1), pp. 449-470. Hindustan Times (2013)

[12] Madhusudhan, V. G. \& Nagaraju, K. (2013): Work Life Balance of Teaching Faculty with Reference to Andhra Pradesh Engineering Colleges. Global Journal of Management and Business Studies, Vol. 3, No. 8, pp. 891-896.

[13] Santhana, L. K., Gopinath S. S. (2013). Work Life Balance of Women Employees with reference to Teaching faculties. International Monthly Refereed Journal of Research in Management and Technology-II.

[14] Ramanithilagam V; Dr.C.S.Ramanigopal (2012): Role of Emotional Intelligence In Work/Life Balance of Women Employees, South Asian Journal of Marketing \& Management Research, Vol.2 (4), pp. 207-214

[15] Rajadhyaksha. U. and Velgach. S. (2009): Gender, gender-role ideology and work-family conflict in India. Paper presented at the annual meeting of the Academy of Management, Chicago, USA. 